\title{
The nature of the alkaline phosphatases of bile
}

\author{
C. P. PRICE, P. G. HILL, AND H. G. SAMMONS \\ From the Department of Clinical Chemistry, East Birmingham Hospital, Birmingham
}

SYNOPSIS The main alkaline phosphatase isoenzymes of human bile have been purified by DEAEcellulose chromatography. Characteristics of the isoenzymes, such as electrophoretic mobility before and after butanol extraction, Michaelis constant, and change in electrophoretic mobility following exposure to neuraminidase have been studied and compared with isoenzymes from other sources.

The results show that the main alkaline phosphatase of bile is derived from the liver. It is present as a protein phosphatidylcholine complex.

The presence of alkaline phosphatase (E.C.3.1.3.1., AP) in the bile is well documented but the source of the enzyme has never been convincingly demonstrated. In the past it was thought that the alkaline phosphatase activity of the bile was derived from the serum (Gutman, 1969). However, more recently several workers, using a variety of techniques, have shown differences between the main AP isoenzymes present in serum and bile. Starch gel electrophoretic studies indicate that the main alkaline phosphatase isoenzyme present in the bile differs from that present either in the serum (Pope and Cooperband, 1966) or in the liver tissue (Chiondussi, Greene, and Sherlock, 1962; Hill and Sammons, 1967).

During preliminary experiments aimed at a technique for removing contaminating AP from 5 '-nucleotidase in hepatic bile it was observed by Hill and Sammons (1969) that extraction with butan -1-o1 caused a considerable increase in AP activity in the aqueous phase. Gall bladder bile was subsequently found to be similarly activated by such treatment. Further, it was found that the extraction led to a change in the electrophoretic mobility, from the origin to a position corresponding to the $\beta$ globulins. It was felt that a study of the characteristics of the AP isoenzymes of bile, before and after extraction, might yield valuable information as to the structural complexity of the alkaline phosphatase in the bile.

\section{Materials and Methods}

Specimens of hepatic bile were obtained from patients with T-tube drainage of the common bile duct after cholecystectomy. Gall bladder bile was obtained Received for publication 15 July 1971. from postmortem cases with no evidence of liver disease.

The commercially available EEL electrophoresis apparatus was used for horizontal starch gel electrophoresis following the principles of Smithies (1955). Details of the method and qualitative and quantitative procedures for localizing AP activity after electrophoresis have been described elsewhere (Hill and Sammons, 1967).

Samples of hepatic bile were shaken for five minutes with an equal volume of n-butanol. They were centrifuged in an MSE Super Minor centrifuge for $10 \mathrm{~min}$, after which time the butanol and aqueous phases had separated.

Alkaline phosphatase estimations were carried out on the original specimens and on the aqueous phases for each sample by the method of Kind and King (1954) with the addition of $40 \mathrm{mM} \mathrm{Mg}^{++}$. Results are reported in King-Armstrong (KAU) units/100 ml.

To purify the AP isoenzymes of bile a basic protein, salmine sulphate, was used to remove pigment and lipid. It was found, using several specimens of either gall bladder or hepatic bile, that it was possible to precipitate $98 \%$ of the pigment whilst retaining the enzyme in the supernatant. Different specimens of bile required differing concentrations of salmine sulphate to complete the separation without loss of enzyme activity. An example of the effectiveness of this technique is shown in Figure 1. Equal volumes of bile and aqueous salmine sulphate concentration were thoroughly mixed in a centrifuge tube. The mixture was centrifuged for 15 minutes at $7,000 \mathrm{rpm}$ in an MSE, Super Minor centrifuge. The supernatant was removed and concentrated by negative 


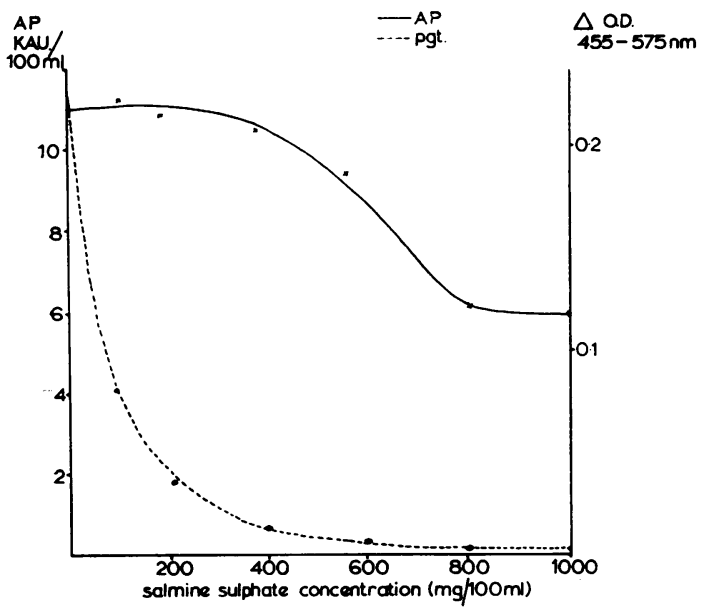

Fig. 1 Alkaline phosphatase activity and pigment concentration (pgt.) after treatment of hepatic bile with salmine sulphate.

pressure ultrafiltration in Visking tubing at $4^{\circ}$ to give a solution with an AP activity of about $200 \mathrm{KAU} /$ $100 \mathrm{ml}$. The concentrated solution $(0.75 \mathrm{ml})$ was applied to a column $(12 \times 1.75 \mathrm{~cm})$ of DEAEcellulose (DE-52, Whatman Column Chromedia) and eluted by an increasing concentration of sodium chloride in $0.01 \mathrm{M}$ Tris- $\mathrm{HCl}$ buffer, $p \mathrm{H} 7 \cdot 4$. Fractions $(2 \mathrm{ml})$ were collected, after monitoring the eluate at $280 \mathrm{~nm}$ using a Uvicord (LKB Producter, Stockholm). Alkaline phosphatase activity and chloride concentrations of the fractions were measured.

Alkaline phosphatase activity was found between chloride concentrations of $0.06 \mathrm{M}$ and $0.11 \mathrm{M}$ and between $0 \cdot 12 \mathrm{M}$ and $0 \cdot 17 \mathrm{M}$. These fractions were separately pooled and concentrated under negative pressure at $4^{\circ}$. The two concentrates were designated fractions 1 and 2 respectively.

The mobility of these two fractions was studied using the quantitative localization technique after starch gel electrophoresis. The effect of butanol extraction on the activity and mobility of the fractions was also observed.

The effect of neuraminidase on the electrophoretic mobility of fractions 1 and 2 and fraction 2 after butanol extraction was studied. The details of the method involved are published elsewhere (Hill and Sammons, 1967). The changes were cc mpared with that of liver AP obtained from a crude homogenate. Following electrophoresis, the isoenzymes were localized qualitatively as described previously.

As a further means of characterizing bile AP the Michaelis constants of the two bile fractions, 1 and 2 , and the corresponding fractions from serum were determined. For this latter purpose a sample of blood was obtained from a patient with an hepatobiliary disorder. This serum was found to contain one AP isoenzyme corresponding in electrophoretic mobility to that of the bile fraction 1. DEAE cellulose chromatography was carried out to purify partially the isoenzyme and a serum isoenzyme corresponding to the bile fraction 1 was obtained. The Michaelis constants of the bile fractions 1 and 2 and serum fraction 1 were determined by increasing enzyme activity at various substrate concentrations over the range 0.43 to $8.60 \mathrm{mM}$. The constant was also determined for the bile fraction 2 after butanol extraction.

In view of the close association of many enzymes with lipids it was decided to expose the butanol soluble extract of bile to thin-layer chromatography in two solvent systems. After concentration by evaporation at room temperature in an atmosphere of nitrogen, extracts of bile fractions 1 and 2 were first chromatographed in a solvent system suitable for general lipid analysis (Lines, 1963). Secondly they were chromatographed in a system designed to separate the classes of phospholipid (Skipsky, 1964). Lipids were located by spraying with $50 \%$ sulphuric acid and charring. Phospholipids were localized $\vec{\theta}$ with iodine and a modified Dragendorf reageng $N$ (Randerath, 1968). Standards were run in each cas using for general lipid analysis mono-, di-, arfe triglycerides prepared from clive oil (Sammons, Frazer, and Thompson, 1956), cholesterol stearate, cholesterol, phospholipid and taurocholic acid, and for phospholipids phosphatidyl ethanolamine, phosphatidyl inositol, phosphatidyl choline, and lysophosphatidyl ethanolamine.

\section{Results}

The alkaline phosphatase isoenzyme electrophoretic patterns and other properties studied were found to be identical in either gall bladder or hepatic bile. $ᄋ$ Ten samples of hepatic bile were studied, the range of activation of the enzyme being between 45 and 음 $75 \%$ and the average increase from $49 \cdot 8$ to $75 \cdot 3$ D KAU. No activity was found in the butanol phase or the resuspended material from the interface. The $N$ activation of gall bladder AP was in the range of $78^{\circ}$ and $88 \%$ in the five specimes studied, the average $N$ increase being from 71.5 to $134 \mathrm{KAU}$. No activity $\tilde{\omega}^{N}$ was found in the butanol phase or the resus- $-{ }_{-}$ pended material from the interface. The AP iso-o enzyme patterns by the quantitative localization technique for hepatic bile before and after butanol $\stackrel{?}{?}$ extraction are shown in Figure 2.

Table I shows AP, protein, lipid, and bilirubin $\frac{0}{+}$ concentrations in gall bladder bile and at different 


\begin{tabular}{|c|c|c|c|c|}
\hline Sample & $\begin{array}{l}\text { Alkaline Phosphatase } \\
(\text { KAU/100 ml) }\end{array}$ & $\begin{array}{l}\text { Protein } \\
(\mathrm{mg} / 100 \mathrm{ml})\end{array}$ & $\begin{array}{l}\text { Lipid } \\
(\mathrm{mg} / 100 \mathrm{ml})\end{array}$ & $\begin{array}{l}\text { Bilirubin } \\
(\mathrm{mg} / 100 \mathrm{ml})\end{array}$ \\
\hline $\begin{array}{l}\text { Original gall bladder bile } \\
\text { Bile after salmine sulphate }\end{array}$ & 314 & 3,370 & 3,600 & 204 \\
\hline $\begin{array}{l}\text { ( } 200 \mathrm{mg} \%) \\
\text { Concentrated fraction } 1 \\
\text { Concentrated fraction } 2\end{array}$ & $\begin{array}{l}157 \\
31 \cdot 5 \\
27 \cdot 5\end{array}$ & $\begin{array}{r}515 \\
11 \\
34\end{array}$ & $\begin{array}{r}385 \\
25 \\
27\end{array}$ & $\begin{array}{l}18 \cdot 4 \\
\text { Nil } \\
\text { Nil }\end{array}$ \\
\hline
\end{tabular}

Table I Alkaline phosphatase, protein, lipid, and bilirubin concentrations during purification of gall bladder bile alkaline phosphatase

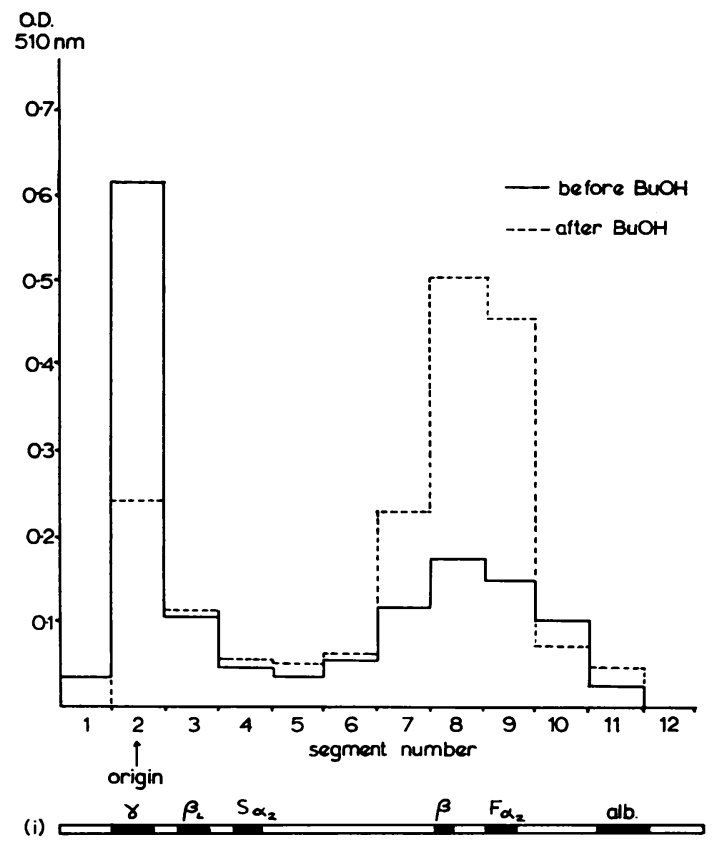

(ii)

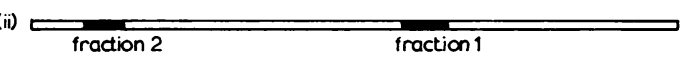

Fig. 2 Quantitative localization of alkaline phosphatase isoenzymes in hepatic bile before and after butanol extraction.

Relative positions of segments and of fractions 1 and 2 (ii) to normal serum proteins $(i)$.

stages during the purification procedure. Recovery of AP from the DEAE cellulose column was $76 \%$ with a 30-fold increase in specific activity for fraction 1 and an eight-fold increase for fraction 2.

Quantitative localization of AP, after starch gel electrophoresis, was carried out on fractions 1 and 2 . The results indicate that fraction 1 migrates in the $\beta$-globulin region whilst fraction 2 remains at the origin (Fig. 2). Butanol extraction of fractions 1 and 2, followed by electrophoresis and quantitative localization, indicates that butanol does not affect

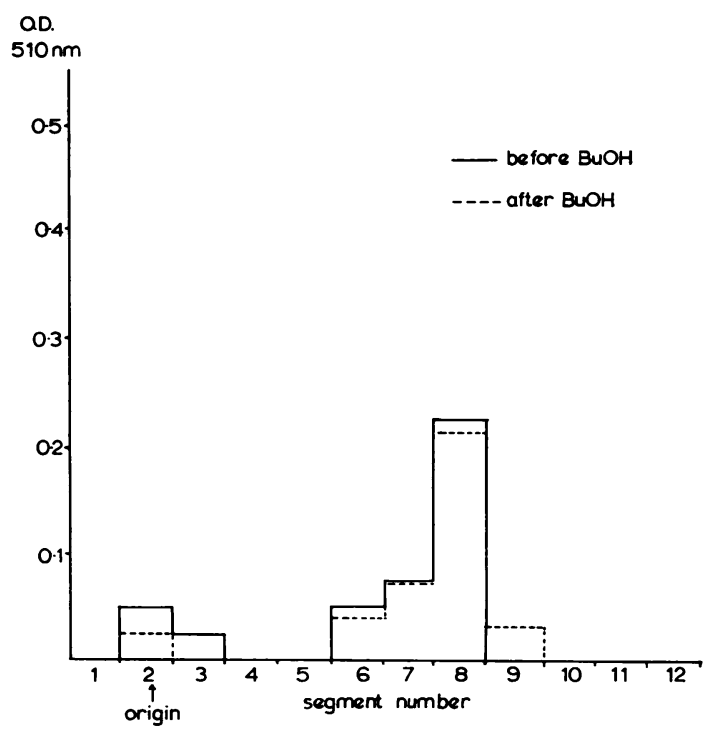

Fig. 3 Quantitative localization of $\beta$-globulin alkaline phosphatase (fraction 1) from bile before and after butanol extraction.

the activity or mobility of fraction 1 (Fig. 3) but increases the activity of fraction 2 while also increasing its electrophoretic mobility to that of fraction 1 (Fig. 4).

Incubation of the AP fraction 2 following treatment with butanol with hepatic bile containing fraction 1 resulted in no change in electrophoretic mobility. Each isoenzyme fraction retained its original mobility in the incubation mixture.

Incubation with neuraminidase caused a decrease in the electrophoretic mobility of the $\beta$-globulin AP isoenzyme; this corresponded to the result found using the AP present in the liver homogenate. The mobility of the AP remaining at the origin was not altered by neuraminidase. However, when the bile fraction 2 was extracted with butanol and then incubated with neuraminidase it showed a decrease in mobility identical to that of bile fraction 1 . These results are shown in Tab!e II and are expressed as. 


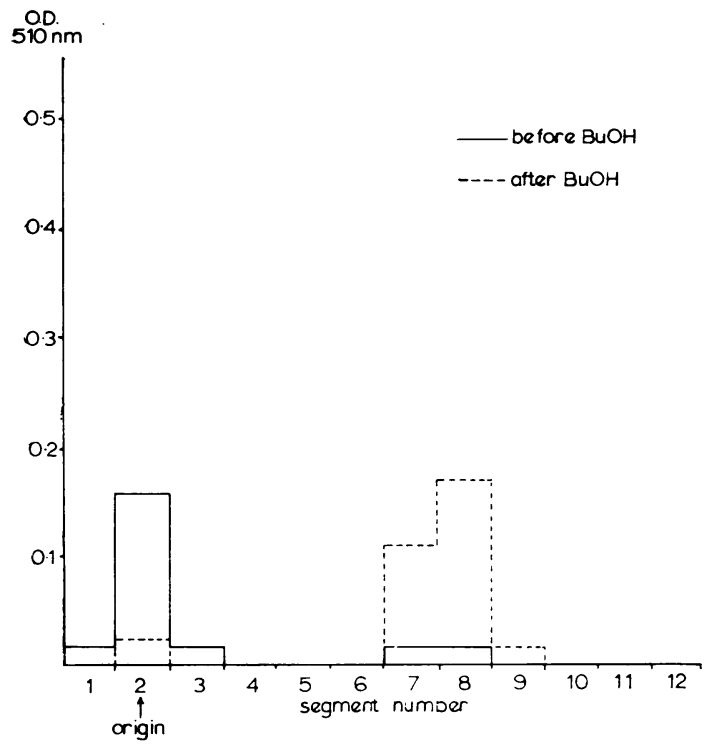

Fig. 4 Quantitative localization of $\gamma$-globulin alkaline phosphatase (fraction 2) from bile before and after butanol extraction.

\begin{tabular}{llll}
\hline Specimen & \multicolumn{2}{l}{ Alkaline Phosphatase Activity } & $\begin{array}{l}\text { Ratio } \\
\text { T/C }\end{array}$ \\
\cline { 2 - 3 } & $C(\mathrm{~cm})$ & $T(\mathrm{~cm})$ & \\
\hline Bile $\beta$-globulin AP & $9 \cdot 6$ & 6.9 & 0.72 \\
Bile $\gamma$-globulin AP & 0.2 & 0.2 & 1.00 \\
Liver homogenate AP & 9.4 & 6.7 & 0.73 \\
Bile $\gamma$-globulin AP after & 9.4 & 6.8 & 0.73 \\
butanol & 9.4 & & \\
\hline
\end{tabular}

Table II The effect of neuraminidase on the mobilities of liver and bile alkaline phosphatase

the ratio of the distance moved by the test (incubated with neuraminidase) over the distance moved by the control (incubated with inactivated neuraminidase).

The $K_{m}$ values for the AP of bile fractions 1 and 2 and a serum fraction 1 were calculated from a Lineweaver-Burke plot of $1 / \mathrm{v}$ against $1 / \mathrm{s}$. The value was also determined for bile fraction 2 following butanol extraction. The reciprocal plots are shown in Fig. 5, where it can be seen that butanol extraction lowers the $\mathrm{K}_{\mathrm{m}}$ of fraction 2 to equal that of fraction 1 and the equivalent fraction 1 of serum. The $K_{m}$ values are summarized in Table III.

The thin-layer chromatography carried out on the butanol extract of bile fractions 1 and 2 indicated the presence of a phospholipid in the fraction 2 solvent phase. Further chromatography in a second solvent system showed this component to be a phosphatidyl-choline. The fraction 1 solvent phase yielded no detectable lipid component.

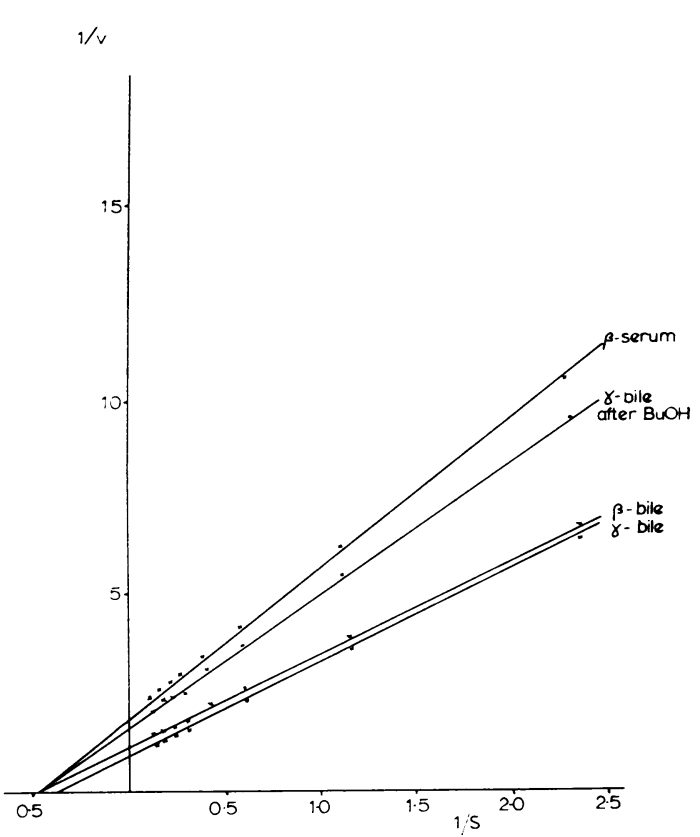

Fig. 5 Graph of $1 / v$ against $1 / s$ for alkaline phosphatase isoenzymes.

\begin{tabular}{ll}
\hline Specimen & $K_{\mathrm{m}}$ Value $(\mathrm{mM})$ from Plot of 1/v against \\
\hline Bile $\beta$-globulin AP & 2.08 \\
Bile $\gamma$-globulin AP & 2.63 \\
Serum $\beta$-globulin AP & 2.00 \\
Bile $\gamma$-globulin AP & 2.08 \\
after butanol & 2.08 \\
\hline
\end{tabular}

Table III $K_{\mathrm{m}}$ values of the alkaline phosphatases of bile and serum.

\section{Discussion}

In the past the origin of the bile alkaline phosphatase has been in some doubt. Dalgard (1949), using biliary fistula dogs, found that serum and bilealkalineo phosphatase were inversely related and concluded that the bile AP was derived from the serum. Le․ Veen, Talbot, Restuccia, and Barberio (1950) claimed that they could quantitatively recoveros intravenously injected alkaline phosphatase activity from the bile of dogs. However, two years previouslyN్ Cantarow and Miller (1948) had shown that in-o creased serum levels of AP did not result in increase levels of AP in the bile. More recent work by Clubb, Neale, and Posen (1965) supports this evidence.

It has been held by many workers that the AP of bile is of osseous origin, the bile being an excretoryo route for this enzyme (Gutman, 1959); this stems from the belief that the AP of serum is of osseous 
origin. However, consistent qualitative differences have been demonstrated between the AP circulating in patients with hepatobiliary disorders and that in the serum of patients with skeletal disorders (Hodson, Latner, and Raine, 1962; Clubb et al, 1965). These differences can be demonstrated by heat inactivation (Clubb et al, 1965), by chemical inactivation (Fennelly, Fitzgerald, and McGeeney, 1966), and by some workers using starch gel electrophoresis (Hodson et al, 1962).

As pointed out by Pope and Cooperband (1966), 'proof of transfer of the serum AP into the bile requires that the serum AP has some unique characteristic'. Several characteristics are available so that the isoenzyme can be recognized. The isoenzyme separation on starch gel electrophoresis is one such characteristic. Several workers have demonstrated marked differences in the electrophoretic mobility of serum and bile AP (Pope and Cooperband, 1966; Hill and Sammons, 1967). Studies involving the examination of several bile samples (Hill and Sammons, 1967) indicate that the main AP isoenzyme of bile migrates with the $\gamma$-globulins on electrophoresis.

The studies of the Michaelis constants of the bile and serum AP isoenzymes indicate a difference in the constant for the $\beta$ - and $\gamma$-globulin AP isoenzymes of bile, with a similarity between the $\beta$-globulin isoenzymes of bile and serum in liver disease. The use of a constant $p \mathrm{H}$ throughout this type of study has been questioned (Motsok and Branion, 1959; Moss, Canıpbell, Anagnostou-Kakaras, and King, 1961). It was felt by the former authors that $K_{m}$ values obtained at a constant $p \mathrm{H}$ were not comparable because of the effect of differing $p \mathrm{H}$ optima existing between phosphatases of different sources even at a constant enzyme concentration. The results presented here regarding substrate affinity, as expressed by the $K_{m}$ value, make two points: first that the $\beta$ globulin AP from bile has a $K_{m}$ value corresponding to that of the $\beta$-globulin AP of serum in liver disease, which one can safely take as being of hepatic origin, and, secondly, that the $\gamma$-globulin AP from bile has a lower substrate affinity compared to the $\beta$-globulin isoenzyme. Butanol extraction changes the $K_{m}$ value, indicating an increase in substrate affinity which is supported by an apparent activation of the enzyme.

The action of neuraminidase on the AP isoenzymes indicates that the $\beta$-globulin AP of bile is derived from the liver. Butanol extraction of the $\gamma$-globulin AP of bile caused a change in electrophoretic mobility of the enzyme, the action of neuraminidase on this component indicating that it too is derived from the liver.

It would appear from the incubation experiment with bile that the re-establishment of the protein complex is not an easily reversible process. This supports our previous observations (Hill and Sammons, 1967).

The butanol phase following extraction of the bile $\gamma$-globulin AP has been shown to contain a phospholipid of the choline group. Our conclusion is that the $\gamma$-globulin AP of bile is a protein-lipid complex involving the liver $\beta$-globulin AP and a phosphatidyl-choline. It would appear that removal of the phosphatidyl-choline by treatment with butanol increases the total negative charge on the protein molecule whilst exposing more active sites on the enzyme molecule.

From this study it would appear that the alkaline phosphatase isoenzyme of the bile, while not being identical with the liver isoenzyme, is nevertheless derived from the liver. The passage from the liver cell to the bile in some way involves the addition of a phosphatidyl-choline to the enzyme molecule. Whether or not this is functional or adventitious remains to be determined.

\section{References}

Cantarow, A., and Miller, L. L. (1948). Nonexcretion of jaundiceserum alkaline phosphatase in bile of normal dogs. Amer. $J$. Physiol., 153, 444-446.

Chiondussi, L., Greene, S. F., and Sherlock, S. (1962). Serum alkaline phosphatase fractions in hepato-biliary and bone diseases. Clin. Sci., 22, 425-434.

Clubb, J. S., Neale, F. C., and Posen, S. (1965). The behavior of infused human placental alkaline phosphatase in human subjects. J. Lab. clin. Med., 66, 493-507.

Dalgaard, J. B. (1949). Serum and bile phosphatase in biliary fistula dogs. Acta physiol. scand., 16, 293-307.

Fennelly, J. J., Fitzgerald, M. X., and McGeeney, K. (1969). Value of differential thermostability, urea inhibition and gel filtration of alkaline phosphatase in the identification of disease states. Gut, 10, 45-51.

Gutman, A. B. (1959). Serum alkaline phosphatase activity in diseases of the skeletal and hepatobiliary systems. Amer. J. Med., 27, 875-901.

Hill, P. G., and Sammons, H. G. (1967). An interpretation of the elevation of serum alkaline phosphatase in disease.J. clin. Path., 20, 654-059.

Hill, P. G., and Sammons, H. G. (1969). Further studies on human alkaline phosphatase and 5'-nucleotidases. Enzymol.biol. clin., 10,401 .

Hodson, A. W., Latner, A. L., and Raine, L. (1962). Iso-enzymes of alkaline phosphatase. Clin. chim. Acta, 7, 255-261.

Kind, P. R. N., and King, E. J. (1954). Estimation of plasma phosphatase by determination of hydrolysed phenol with aminoantipyrine. J. clin. Path., 7, 322-326.

LeVeen, H. H., Talbot, L. J., Restuccia, M., and Barberio, J.R. (1950). Metabolism and excretion of alkaline phosphatase. Relation of liver-function and determination of maximal secretory rates of liver. J. Lab. clin. Med., 36, 192-205.

Lines, J. G. (1963). In Biochemical Problems of Lipids, edited by A. C. Frazer, pp. 17-23. Elsevier, Amsterdam.

Moss, D. W., Campbell, D. M., Anagnostou-Kakaras, E., and King, E. J. (1961). Characterization of tissue alkaline phosphatases and their partial purification by starch gel electrophoresis. Biochem. J., 81, 441-447.

Motzok, I., and Branion, H. D. (1959). Studies on alkaline phosphatases. II. Factors influencing $\mathrm{pH}$ optima and Michaelis constant. Biochem. J., 72, 177-183.

Pope, C. E., II, and Cooperband, S. R. (1966). Protein characteristics of serum and bile alkaline phosphatase. Gastroenterology, 50 631-636. 
Randerath, K. (1968). In Thin Layer Chromatography, 2nd ed., p. 154. Academic Press, London.

Sammons, H. G., Frazer, A. C., and Thompson, M. (1956). The estimation of true lipase in small intestinal contents. J. clin. Path., 9, 379-380.
Skipski, V. P., Peterson, R. F., and Barclay, M. (1964). Qualitative analysis of phospholipids by thin-layer chromatography. Biochem. J., 90, 374-378.

Smithies, O. (1955). Zone electrophoresis in starch gels: group variations in the serum proteins of normal human adults. Biochem. J., 61, 629-641. 